\title{
POPULAÇÃO NEM-NEM: uma análise a partir dos dados da PNAD 2012
}

\section{NEET POPULATION: an analysis from the National Household Sample Survey 2012}

Adriano Marcos Rodrigues Figueiredo ${ }^{1}$ Jessika Brenner Soares Araújo de Almeida ${ }^{2}$

\begin{abstract}
Resumo: Este trabalho objetivou estudar o subgrupo populacional dos jovens de modo que se possa identificar quem entre eles e por que estão na condição "NemNem". Especificamente, objetivou-se: identificar os aspectos gerais desta população comparando os resultados existentes para o caso do Brasil, América Latina e OCDE; identificar as principais características desta população e traçar um perfil desses jovens; comparar o perfil característico desses jovens, através dos dados da PNAD; e, mensurar as variáveis mais influentes à condição "Nem-Nem". O estudo revelou que a grande maioria dos jovens que estão na condição NemNem, são mulheres. O modelo probit foi utilizado e nas variáveis com influência negativa, ou seja, aquelas que influenciarão o indivíduo a não estar na condição estudada, estão a maioria das variáveis do modelo, sendo elas: "sexo", "escolaridade", "renda", "ler/escrever", "internet", "desquitado", "divorciado", "solteiro". As variáveis "idade", "domestico", "morar com a mãe", "ter filho" e "cor branca" são as com influência positiva, aquelas que contribuirão para indivíduo estar na condição Nem-Nem.
\end{abstract}

Palavras-chave: trabalho, educação, exclusão.

Classificação JEL: J01, O15

Abstract: This study aimed to study the population subgroup of young people so that one can identify who and why among them is in the NEET condition. Specifically, the objective was to: identify the general aspects of this population comparing the existing results for the case of Brazil, Latin America and OECD; Identify the main characteristics of this population and draw a profile of these young people; Compare the characteristics of these young people, through NHSS data; and measure the most influential variables to the NEET patterns. The study revealed that the vast majority of young people who are in the NEET profile are women. The probit model was used and the variables with negative influence, that is, those that influence the individual not to be in the NEET group, are most of the variables: "sex", "schooling", "income", "Read / write", "internet", "rehabbed", "divorced", "single". The variables "age", "domestic", "living with the mother", "having child" and "white color" are those with positive influence, those that will contribute to the individual being NEET.

Keywords: labor, education, exclusion

JEL Codes: J01, O15

\footnotetext{
${ }^{1}$ Doutor em Economia Aplicada pela UFV. Economista e engenheiro civil. Pesquisador em Desenvolvimento e Economia Regional. Professor da UFMS. E-mail: adriano.figueiredo@ufms.br. ${ }^{2}$ Economista pela UFMS. E-mail: jessika_brenner@hotmail.com.
}

Revista de Estudos Sociais | Ano 2017, N. 38, V. 19, Pag. 106 


\section{INTRODUÇÃO}

O Brasil possuía cerca de 48 milhões de jovens entre 15 a 29 anos, de acordo com a Pesquisa Nacional de Amostragem de Domicílios de 2012 (IBGE, 2012), ou seja, cerca de $25,3 \%$ da população é jovem. Entre os anos de 2000 e 2010, observou-se um aumento no número de pessoas dessa faixa etária que não estudavam e nem trabalhavam, a chamada população "Nem-Nem" (termo utilizado no Brasil) ou NEET (not in education, employment or training, no padrão internacional), ou Ni-Ni na literatura em espanhol. Ao longo do texto usa-se o termo "Nem-Nem" e "NEET", para referir os jovens que estão afastados da escola e do mercado de trabalho.

Um problema que atinge tanto os países em desenvolvimento quanto países desenvolvidos, os NEETs vêm despertando a atenção em todo o mundo. A Secretária de Avaliação e Gestão da Informação (SAGI) pontua que com o início da crise financeira internacional em 2008, houve agravamento da situação de desemprego, principalmente entre os jovens (MDS, 2013a). Cardoso (2013) e Quarina (2017) também evidenciam os impactos das crises e ciclos econômicos de negócios sobre a condição de ser Nem-Nem.

\section{A Organização para a Cooperação Econômica e o Desenvolvimento} (OCDE) (OECD, 2012) estima que dois anos após o início da crise (2010) a taxa de jovens desempregados ou inativos entre 15 e 29 anos de idade, e que também não estavam na escola, já atingia 15,8\% nos países da OCDE, alcançando o maior índice na Turquia (36,6\%), Israel (27,4\%), México (24,4\%) e Espanha $(23,7 \%)$. Entre os 21 países analisados na União Europeia a média no mesmo ano foi de $14,8 \%$. O Brasil se examinado utilizando o mesmo conceito de NEET da OCDE aparece com 19,6\%.

Para Organização Internacional do Trabalho (OIT, 2013), na América Latina cerca de 21,8 milhões de jovens, entre 15 a 24 anos não estudam e nem trabalham. Todavia, é importante ressaltar que nos países da OCDE, a crise do emprego é central. Diferentemente que no Brasil, cuja desigualdade social fortemente marcada pela diferença de renda das famílias, e consequentemente a pobreza, assume papel central na definição do fenômeno dos "Nem-Nem", como apontado no estudo técnico do Ministério do Desenvolvimento Social e Combate à Fome (MDS, 2013b).

O "Nem-Nem" é aquele jovem que não está no mercado de trabalho e também não tem vínculo com nenhuma instituição de educação. Porém, é importante levar em consideração que o Nem-Nem pode ser aquele indivíduo que está afastado do trabalho ou dos estudos por estarem em cuidando dos idosos, doentes ou até crianças. No caso das mulheres, muita delas, como será dito adiante, deixam de trabalhar para ficar em função dos seus filhos ou de afazeres domésticos.

De acordo com o Instituto Internacional de Planejamento da Educação (IIPE), conforme citado pelo MDS (2013a), estima-se que na América Latina 22\% das jovens entre 15 e 29 anos se dedicam exclusivamente aos afazeres domésticos, entre os jovens do sexo masculino, a porcentagem cai para 1,4\%. Há jovens que por estarem no período de transição escola/mercado de trabalho, tem o apoio dos pais, seja para fazer intercâmbio, viagens ou atividades de voluntariado, sem ter vínculo empregatício ou educacional. Exemplos como 
esses, que mostram situação onde o indivíduo não possui vinculo de trabalho e nem educacional, são capturados pelas pesquisas domiciliares, mas não caracterizam inatividade ou ociosidade do jovem.

Cardoso (2013) afirma que a crise econômica de 2008 ascendeu uma luz vermelha em relação aos jovens e o mercado de trabalho. A condição "ni ni" outra denominação espanhola para os jovens que não estão nem na escola e nem trabalhando - antes vista como típica dos países do sul da Europa, como Espanha, Itália e Portugal, disseminou-se pelo continente (Pardo, 2010).

Assim como nos países do continente europeu a condição "Nem-Nem" vem cada vez mais ganhando espaço no Brasil. Principalmente pelo fato de seu contingente estar em ascensão, conforme dados da PNAD (IBGE, 2012), esta população já atingiu os 9,6 milhões. É por entender a seriedade deste problema e a proporção que vem tomando nos últimos anos que este trabalho busca analisar o perfil do jovem brasileiro que está nessas condições. Entender quem são esses jovens, como é o lar onde eles vivem e como é a formação de suas famílias, são questões primordiais para uma análise inicial do problema.

Vários autores como: Coles et al. (2002), Pardo (2010), Dorsett e Lucchino (2012), apontam sérias consequências de longo prazo decorrentes deste fenômeno, como: maior probabilidade de se tornarem desempregados, de usar drogas e álcool, gravidez na adolescência e envolvimento no crime. Para Camarano e Kanso (2012), os jovens não deixam de procurar trabalho por desalento, não estudam por falta de renda e/ou de perspectivas futuras ou, diferentemente, estão inseridos em uma família capaz de garantir a sobrevivência básica até conseguirem uma posição satisfatória no mercado de trabalho.

Entre os anos de 2000 e 2010, observou-se um aumento no número de indivíduos que não estudavam e nem trabalhavam na faixa de idade entre 15 e 29 anos: eram 8,123 milhões de pessoas em 2000, e passou para 8,832 milhões em 2010. Conforme dados da Pesquisa Nacional de Amostras Domiciliares de 2011, há outros 1,7 milhão de adolescentes dessa faixa etária longe das escolas, um contingente que pode ajudar a aumentar a geração dos "Nem-Nem".

O perfil da renda é um forte indicador para tentar entender o comportamento dos jovens que não estudam e não trabalham. Podendo identificar duas situações distintas: indivíduos oriundos de famílias de baixa renda e indivíduos que, independentemente da família de origem, têm baixa renda por estarem constituindo família. Estes jovens podem ter dificuldades no acesso e permanência na escola ou não têm a educação básica completa.

O objetivo desta pesquisa foi delineado na intenção de estudar o subgrupo populacional dos jovens de modo que se possa identificar quem entre eles e por que estão na condição "Nem-Nem". O objetivo geral desta pesquisa consiste em traçar o perfil do jovem brasileiro pertencente ao grupo dos "Nem-Nem" juntamente com a identificação da influência que cada variável tem sobre o fato do jovem estar ou não nesta condição. Dentre os objetivos específicos, pretendese: a. identificar os aspectos gerais desta população comparando os resultados existentes para o caso do Brasil, América Latina e OCDE; b. identificar as principais características desta população e traçar um perfil desses jovens; c. comparar o perfil característico desses jovens, através dos dados da PNAD; e, d. mensurar as variáveis mais influentes à condição "Nem-Nem". 
Por ser um tema relativamente recente, onde não se encontra muitas referências bibliográficas sobre o assunto, esse trabalho buscou traçar o perfil do subgrupo populacional comparando com dados de outras organizações internacionais. A grande maioria dos principais autores escreve sobre a transição para a vida adulta e evolução dos jovens "Nem-Nem" após 2001, ano onde os jovens que estavam fora do mercado trabalho e fora das escolas começaram a ser observados.

Pesquisadores como Camarano e Kanso (2012), discorreram em seus estudos sobre a transição para a vida adulta do jovem, politicas sociais e alocação do tempo dos jovens. Vieira (2009) publicou trabalhos referentes à transição para a vida adulta e quem eram os jovens Nem-Nem. Mais recentemente, Tillmann (2013) e Tillmann e Comim (2016) fizeram um trabalho sobre a desigualdade, escolaridade e rendimentos dos jovens no Brasil, fazendo um estudo também dos jovens que estão na condição Nem-Nem, mas vivem em meio rural. Em geral, as consequências de ficar muito tempo na condição NemNem pode inviabilizar o acesso ao mercado de trabalho de modo definitivo, levando essas pessoas à indigência social, ou a uma vulnerabilidade social crítica.

O presente trabalho contribui para a literatura ao utilizar os micro dados da PNAD 2012, diferentemente dos autores supracitados, cujos dados são da PNAD 2011, para o Brasil, com uma modelagem econométrica multivariada do tipo probit.

No próximo capítulo, apresenta-se o referencial teórico, seguido do capítulo de método e dados, dos resultados e discussão e, por fim, as conclusões.

\section{O FENÔMENO NEM-NEM: NEM ESTUDA-NEM TRABALHA}

Os primeiros indícios do fenômeno Nem-Nem foram identificados em meados da década de 90. Na América Latina, só recentemente que essa questão foi incorporada ao debate público, embora ainda existam dificuldades no âmbito das políticas públicas.

Tillmann (2013), afirma que este grupo representa um dos maiores desafios contemporâneo para o desenvolvimento, por estar relacionado com consequências negativas. Cardoso (2013) argumenta que a "condição Nem-Nem" é fruto da junção de duas determinantes: a primeira são os contextos de inserção social dos jovens, como a família, o sistema escolar e o mercado de trabalho; e a segunda, das trajetórias dos indivíduos. Entre 2008 e 2010, houve um aumento na proporção dos jovens que permaneciam na escola, concomitantemente adiando a entrada no mercado de trabalho, desta forma o aumento dos "NemNem", deveu-se, quase exclusivamente, ao desemprego de jovens antes ocupados, e que já tinham deixado à escola.

Cardoso (2013, p. 296), conclui que:

Desse ponto de vista, parte do fenômeno midiaticamente tratado como novo, que estaria afetando de forma diferenciada uma geração específica, agora rotulada de "geração Nem-Nem", na verdade é desemprego juvenil em larga escala, ocorrendo entre

Revista de Estudos Sociais | Ano 2017, N. 38, V. 19, Pag. 109 
jovens que já haviam deixado a escola para trabalhar e que, diante da redução das perspectivas do mercado de trabalho, já não conseguem emprego, ou decidiram, ou estão em condições (tendo em vista as salvaguardas dos estados de bem estar na Europa ou as redes de proteção familiar) de esperar por uma ocupação num futuro melhor.

Como mencionado na introdução, existem diversos estudos (COLES et al., 2002; PARDO, 2010; DORSETT e LUCCHINO, 2012) que apontam as sérias consequências de longo prazo decorrentes deste fenômeno: maior probabilidade de se tornarem desempregados, de usar drogas e álcool, gravidez na adolescência e envolvimento no crime.

Para Cardoso (2013), a condição "Nem-Nem" é um problema social que abrange diversos países. Na Europa, atingiu principalmente a classe média, diagnosticado como um problema geracional e de classe, o que difere com o Brasil, onde os mais atingidos foram às famílias mais pobres e a classe mais baixa.

Elaborou-se na Tabela 1 uma descrição de alguns trabalhos e contribuições nesta área de estudo, embora não seja uma descrição exaustiva, e comentados nas seções que seguem.

Tabela 1. Principais trabalhos associados à temática do Nem-Nem.

(continua)

\begin{tabular}{|c|c|}
\hline Referência & $\begin{array}{l}\text { Fatores estudados e relacionados à condição Nem- } \\
\text { Nem (NEET) }\end{array}$ \\
\hline $\begin{array}{l}\text { 1. Camarano e } \\
\text { Fernandes } \\
(2014)\end{array}$ & $\begin{array}{l}\text { Trabalha com o grupo e } 50 \text { a } 59 \text { anos na condição Nem- } \\
\text { Nem, com dados da PNAD para 1992, 2002, 2012, num } \\
\text { estudo descritivo para o Brasil. }\end{array}$ \\
\hline $\begin{array}{l}\text { 2. Camarano e } \\
\text { Carvalho (2015) }\end{array}$ & $\begin{array}{l}\text { Estudam o grupo de homens na condição Nem-Nem, } \\
\text { com dados da PNAD para 1993, 2003, 2013, Brasil. }\end{array}$ \\
\hline $\begin{array}{l}\text { 3. } \text { Camarano e } \\
\text { Kanso (2012) }\end{array}$ & $\begin{array}{l}\text { Faz estudo descritivo do perfil dos Nem-Nem com } \\
\text { dados da PNAD de } 2001 \text { e } 2011 \text { para o Brasil. }\end{array}$ \\
\hline 4. Cardoso (2013) & $\begin{array}{l}\text { Estuda a crise econômica e a pobreza como problema } \\
\text { social causador da condição Nem-Nem, com um modelo } \\
\text { multivariado logístico multi níveis para o Brasil e micro } \\
\text { dados dos Censos Demográficos de } 2000 \text { e } 2010 \text {. }\end{array}$ \\
\hline $\begin{array}{l}\text { 5. Coles et al. } \\
(2002)\end{array}$ & $\begin{array}{l}\text { Trabalha com dados domiciliares da Inglaterra, } \\
\text { descrevendo e avaliando as consequências de longo } \\
\text { prazo para aqueles em condição Nem-Nem, causados } \\
\text { entre outros fatores pela pobreza, falta de educação } \\
\text { especial, maus resultados educacionais até } 16 \text { anos, } \\
\text { saúde precária, entre outros. }\end{array}$ \\
\hline $\begin{array}{l}\text { 6. Corseuil et al. } \\
(2001)\end{array}$ & $\begin{array}{l}\text { Estuda } 4 \text { países incluindo o Brasil, e utiliza um modelo } \\
\text { logit multinomial econométrico, com as principais } \\
\text { variáveis explicativas sendo a educação dos pais, os } \\
\text { recursos disponíveis, o poder decisório do chefe da } \\
\text { família entre outras variáveis de pesquisas domiciliares }\end{array}$ \\
\hline
\end{tabular}

Revista de Estudos Sociais | Ano 2017, N. 38, V. 19, Pag. 110 


\begin{tabular}{ll|l}
\hline 7. $\begin{array}{l}\text { Dorsett e } \\
\text { Lucchino (2012) }\end{array}$ & $\begin{array}{l}\text { Usa um modelo multi-estado misto para avaliar a } \\
\text { experiência sobre a empregabilidade e a condição Nem- } \\
\text { Nem, no Reino Unido, com dados domiciliares de 1991 } \\
\text { até 2008. }\end{array}$ \\
\hline $\begin{array}{l}\text { 8. Jaccoud et al } \\
\text { (2009) }\end{array}$ & Riscos sociais e a condição de vulnerabilidade social, \\
\hline
\end{tabular}

Tabela 1. Principais trabalhos associados à temática do Nem-Nem.

(conclusão)

\begin{tabular}{|c|c|}
\hline Referência & $\begin{array}{l}\text { Fatores estudados e relacionados à condição Nem- } \\
\text { Nem (NEET) }\end{array}$ \\
\hline 9. Pardo (2010) & $\begin{array}{l}\text { Analisa as consequências de longo prazo para a } \\
\text { condição Ni-Ni (Nem-Nem) em países da América } \\
\text { Latina, com análise descritiva até } 2008 \text { na tentativa de } \\
\text { identificar os fatores micro e macro que levam a esta } \\
\text { condição. }\end{array}$ \\
\hline 10. Quarina (2017) & $\begin{array}{l}\text { É uma tese em economia, que associa não apenas } \\
\text { jovens, mas também adultos, e faz uma análise } \\
\text { temporal considerando os ciclos econômicos de } \\
\text { negócios afetando o NEET, com modelagem logit } \\
\text { multinomial, para o Reino Unido }\end{array}$ \\
\hline $\begin{array}{l}\text { 11. Ralston et al } \\
(2016)\end{array}$ & $\begin{array}{l}\text { Numa análise para a Escócia, com dados censitários } \\
\text { para 1991, } 2001 \text { e } 2011 \text {, e concluem que o gênero e o } \\
\text { alcance educacional afetam a condição Nem-Nem. } \\
\text { Utilizam uma regressão múltipla para explicar um } \\
\text { escore que mede a estrutura ocupacional baseada em } \\
\text { padrões de interação social }\end{array}$ \\
\hline $\begin{array}{l}\text { 12. Sadler et al } \\
\text { (2015) }\end{array}$ & $\begin{array}{l}\text { Analisam a área rural do Reino Unido, concluindo que o } \\
\text { fraco alcance educacional e a baixa condição } \\
\text { socioeconômica seriam os principais determinantes da } \\
\text { condição Nem-Nem. Um estudo descritivo de farto } \\
\text { referencial de base. }\end{array}$ \\
\hline $\begin{array}{l}\text { 13. Samoilenko e } \\
\text { Carter (2015) }\end{array}$ & $\begin{array}{l}\text { Os autores comparam situações de longo tempo como } \\
\text { Nem-Nem em relação a grupos com pequeno tempo } \\
\text { nesta condição, utilizando dados de pesquisas } \\
\text { familiares da Nova Zelândia. O método de propensity } \\
\text { score matching e uma equação tipo logit avaliou as } \\
\text { características de ficar mais ou menos tempo como } \\
\text { Nem-Nem. }\end{array}$ \\
\hline $\begin{array}{l}\text { 14. Tillmann (2013) e } \\
\text { Tillmann e } \\
\text { Comim (2016) }\end{array}$ & $\begin{array}{l}\text { Ressaltam, num estudo econômico, a importância da } \\
\text { educação dos pais e da renda do domicílio sobre a } \\
\text { decisão de acumulação de capital humano dos filhos, } \\
\text { com dados da PNAD 2011, num modelo logit } \\
\text { multinomial. }\end{array}$ \\
\hline
\end{tabular}

Fonte: elaboração própria.

Revista de Estudos Sociais | Ano 2017, N. 38, V. 19, Pag. 111 


\subsection{Nem-Nem: caracterização}

Houve dificuldade para delimitar a faixa etária do grupo de estudo, como nos dados agrupados por idade de algumas bases. A OCDE, por exemplo, utiliza a faixa etária de 15 a 29 anos nas suas estatísticas de NEET.

A Organização Mundial de Saúde fixa como adolescência a faixa etária compreendida entre 10 e 19 anos e como população jovem, o grupo de 10 a 24 anos. Porém, a Secretaria Nacional da Juventude (SNJ) define como jovem, a população com idades entre 15 a 29 anos. De acordo com Vieira (2009), há estudos internacionais que definem o jovem com a faixa etária de 15 a 29 anos, no caso de Portugal, e outros que tem uma faixa etária mais ampla, como o caso do México, onde a faixa etária jovem identificada é de 15 a 34 anos.

Cardoso (2013) propõe como faixa etária de interesse para o estudo da condição juvenil "Nem-Nem", jovens entre 18 e 25 anos. Sustentando que, nessa faixa etária, faz sentido usar o termo "taxa Nem-Nem de exclusão" como uma medida da vulnerabilidade social dos jovens, tendo em vista que aos 18 anos a maioria dos jovens brasileiros já deixou ou está próximo de deixar o ensino médio.

De acordo Cardoso (2013), a taxa de transição para o ensino superior, é historicamente baixa. Assim, ao deixar o ensino médio, significa deixar o sistema escolar e muito provavelmente entrar no mercado de trabalho. Aos 25 anos, segundo o autor, as "taxas de exclusão Nem-Nem" estão estáveis para homens e mulheres, em torno de $11 \%$ no primeiro caso e de $32 \%$ no segundo.

No Brasil, os estudos como de Camarano et al (2004) balizam a idade do jovem entre 15 a 29 anos. De acordo com Assembleia Geral das Nações Unidas de 1985, o limite mínimo seria 15 anos, que estaria em sintonia com o desenvolvimento de funções sexuais e reprodutivas. E o limite superior, 24 anos, refletiria a conclusão da educação formal, inserção no mercado de trabalho e constituição de família.

No Fórum Mundial da Juventude de 2001, o grupo de trabalho pediu às Nações Unidas que reformulassem a sua definição de juventude - que abrange as idades compreendidas entre os 15 e os 24 anos - e aumente o limite superior para os 30 anos, de modo a enfrentar os desafios que se colocam aos jovens, especificamente nos países em desenvolvimento. A classificação considera jovens os "adolescentes-jovens" (15 a 17 anos), os "jovens-jovens" (18 a 24 anos) e os "jovens adultos" (25 a 29 anos) (VIEIRA, 2009). Para Vieira (2009), ao se trabalhar com a definição de população jovem, como sendo de 15 a 29 anos, deve-se levar em conta que muitos desses indivíduos já realizaram as transições mais marcantes da passagem à vida adulta.

Como se pode verificar, não há um consenso de onde termina a juventude, há casos onde relacionam o final desta fase com a primeira união conjugal ou o nascimento do primeiro filho. Vieira (2009) afirma que esta falta de consenso, é resultado de mudança fundamental: o tempo que dura uma transição depende cada vez menos de normatizações fixadas simples e exclusivamente em critérios etários.

\subsection{Transição para a vida adulta}

Revista de Estudos Sociais | Ano 2017, N. 38, V. 19, Pag. 112 
Segundo Vieira (2009), a difusão da escolarização teve o poder de separar as crianças, definidas como indivíduos em formação, dos adultos. Peralva (1997), citado por Vieira (2009), discorre que o ensino seriado transmite justamente a ideia de uma escala, na qual existe uma correspondência idade-série seguindo uma direção linear. Desta forma o indivíduo que conclui os estudos é considerado formado, em relação às crianças ou adolescentes, classificados como indivíduos em formação.

Vieira op. cit. justifica a quebra do processo linear de transição para a vida adulta, com o aumento da expectativa de vida, aliada às novas necessidades e possibilidades, iniciando, desta forma, novos estilos de vida alternativos, que fogem da sequência tradicional: saída da escola, entrada no mercado de trabalho, casamento e nascimento do primeiro filho.

Uma parte expressiva da teoria sobre o curso da vida se fundamenta de uma forma ou outra nos conceitos-chave de trajetória e transições, de acordo com Vieira op. cit. Ao mesmo tempo em que o conceito de trajetória dá conta da dinâmica de longa duração do curso da vida, o conceito de transição dá conta de períodos de guinadas ou ajustes nesta trajetória. Macmillan (2005), citado por Vieira (2009), discorre que transições são períodos mais curtos e circunscritos no tempo, que sinalizam o fim e o início de etapas de uma trajetória.

A decisão a ser tomada para os membros mais jovens da família depende, em última instância, das preferências e de recursos de todos os membros da família, de acordo com Barros, Mendonça e Velazco (1994) apud Corseuil et al (2001).

Corseuil et al. (2001) afirmam que a educação dos pais é apontada como um dos principais determinantes da preferência da família em relação à decisão dos membros jovens. Desta forma, pais mais escolarizados teriam mais informações sobre a importância da educação e tenderiam a atribuir maior valor ao tempo gasto por seus filhos em atividades escolares. Ainda segundo o mesmo autor, na medida em que a educação seja correlacionada com a renda permanente do indivíduo, pais mais educados disponibilizam de mais recursos para investir na educação de seus filhos, aumentando a probabilidade de eles estarem frequentando a escola.

Todavia, os recursos disponíveis para a educação podem não ser distribuídos uniformemente. Para Corseuil et al. (2001, p.5), "a repartição pode levar em consideração os rendimentos potenciais, atuais e futuros de cada membro, determinando assim uma estratégia diferenciada de alocação de tempo para membros da mesma família".

De acordo com Corseuil et al (op. cit.), outros fatores podem ser apontados como relevantes na decisão sobre como os jovens devem alocar seu tempo, um desses fatores é a definição de quem concentra o poder decisório, ou seja, do chefe da família.

"Para alguns estudos assumem que essa escolha cabe ao chefe de família, enquanto outros consideram que há um processo de barganha entre os membros. O fato de haver ou não barganha e o modo como se dá a barganha devem estar relacionados tanto ao tamanho quanto à composição da família" (CORSEUIL et al, 2001, p.6).

Revista de Estudos Sociais | Ano 2017, N. 38, V. 19, Pag. 113 
Outro fator apontado como um determinante a ser considerado na alocação do tempo dos jovens, sobretudo crianças, consiste na tolerância das sociedades ao trabalho infantil, ressalva Lopez-Calva (2000) citado por Corseuil et al. (2001). Isso quer dizer que uma família pode decidir se um jovem trabalhará ou não baseada na expectativa de sofrer retaliações legais ou sociais a essa decisão. Tal tolerância estaria sendo determinada por um conjunto de normas institucionais da sociedade a ser analisada. Essa sociedade formada por famílias cujo vivem em situação de subsistência.

\subsection{Vulnerabilidade Social}

Para Jaccoud et al (2009), o tema do jovem e o estado de vulnerabilidade social vêm ganhando espaço nos debates públicos e se tornando um problema relevante para o Brasil. Políticas públicas, em especial através da Assistência Social, tornam-se cada vez mais presente na tentativa de minimizar esta dificuldade e amenizar a perca que a sociedade tem com tal fato. $O$ jovem em estado vulnerável proporciona grandes perdas à sociedade, tanto no quesito violência e comportamentos de risco, quanto no aumento da desigualdade social existente. Mesmo sem diagnósticos precisos, assim como análises das políticas públicas já em andamento, este tema tem-se imposto progressivamente.

A vulnerabilidade social, segundo Sposati, citado por Jaccoud et al (2009), está relacionada aos riscos sociais e às condições da sua ocorrência. Desta forma, quanto maior o estado de vulnerabilidade que um indivíduo se encontra, maior é sua exposição aos riscos sociais. Entende-se por riscos sociais os eventos que proporcionam privações e danos ao indivíduo e não devem ser associados apenas às situações de pobreza, situações como desemprego, doença, dificuldade de inserção ao mercado de trabalho, deficiência física e outras também devem ser consideradas.

O trabalho das políticas públicas ao abordar os jovens em estado de vulnerabilidade e riscos sociais enfrenta grandes desafios. Alguns destes desafios é o problema em identificar as diversidades existentes neste grupo e mensurar a real necessidade por serviços e benefícios.

[...] No que diz respeito à juventude como público da política de assistência, tanto as vulnerabilidades como os riscos sociais mais frequentes devem ser mais bem conhecidos e analisados, visando organizar ações de prevenção e proteção, assim como de desenvolvimento de capacidades e potencialidades. (JACCOUD et al, 2009, p.172)

Ainda de acordo com Jaccoud et al (op. cit.), os programas de benefícios e segurança de renda cresceram progressivamente na última década, benefícios abrangendo todas as faixas etárias foram iniciados e uma boa parcela da população foi contemplada. No entanto, a especificidade da juventude deve ser destacada. $\mathrm{O}$ jovem encontra-se em um período delicado em relação ao mercado de trabalho, pois, nesta época a busca por autonomia financeira passa a ser a questão central de sua vida e problemas como falta de oportunidade pela falta de

Revista de Estudos Sociais | Ano 2017, N. 38, V. 19, Pag. 114 
experiência, menores remunerações e ocupações precárias são recorrentes. É nesta busca que a fragilidade das trajetórias escolares se mostra como um problema. Os programas de garantia de renda envolvendo os jovens buscam lidar com as dificuldades vividas por eles, na intenção de construir melhores oportunidades e trajetórias profissionais.

A oferta de serviços pelos programas da assistência social depende da identificação das distintas situações, vulnerabilidades e demandas dos jovens. Deste modo, a quase inexistência de diagnósticos e estatísticas para este públicoalvo torna-se um problema em potencial para as determinações das políticas públicas, fazendo com que tais políticas se restrinjam às violações de direto, ausência de convivência social, exposições à violência e outras (JACCOUD et al, op. cit.).

\section{METODOLOGIA}

Esta pesquisa é classificada como uma pesquisa quantitativa descritiva. Para Moresi (2003), a pesquisa descritiva expõe características de determinada população ou de determinado fenômeno. Pode também estabelecer correlações entre variáveis e definir sua natureza. A pesquisa descritiva não tem o compromisso de explicar os fenômenos que descreve, embora sirva de base para tal explicação.

Os dados deste trabalho foram extraídos da Pesquisa Nacional por Amostras de Domicílios (PNAD) do ano de 2012. Realizado atualmente pelo Instituto Brasileiro de Geografia e Estatística (IBGE). A PNAD é uma pesquisa por amostra probabilística de domicílios, com abrangência nacional aplicada anualmente que produz diversos indicadores. . Em 2011, o número de domicílios visitados foram cerca 146 mil domicílios e entrevistadas 359 mil pessoas. Para 2012, foram pesquisadas 362 mil pessoas e 147 mil domicílios distribuídos por todas as Unidades da Federação.

No caso de pesquisas como a PNAD, que são considerados pesquisas como plano amostral complexo, há a necessidade de fazer a expansão amostral. De acordo com o IBGE, a expansão da amostra utiliza estimadores de razão cuja variável independente é a projeção da população residente de cada Unidade da Federação, segundo o tipo de área (região metropolitana e não metropolitana de divulgação da pesquisa). Silva (2002), ressalva que quando são considerados os pessoas das unidades amostrais nos cálculos, as estimativas obtidas para os parâmetros populacionais correspondentes são não viciadas.

Para a expansão da amostra, utilizou o seguinte comando:

svyset [pweight=peso], strata(strat) psu(psu) singleunit(centered)

Para analisar os domicílios com jovens "Nem-Nem" foi utilizado o modelo Probit de análise. Este modelo consiste em estimar a probabilidade de ocorrer um fato decorrente das características definidas como variáveis independentes, tais como variáveis relacionadas à renda, escolaridade, composição familiar entre outras que se julgaram relevantes. Uma das características desse modelo é a 
utilização da variável dependente com natureza binária, ou seja, a escolha faz-se entre duas alternativas onde uma ou outra deverá ser escolhida.

Segundo Costa (2014), são diversos os empregos para os modelos de escolha binária, tais como: nos estudos da oferta de trabalho, onde é frequente modelizar a decisão de participação ou não na força de trabalho como função de uma série de variáveis (sexo, grau de instrução, idade, estado civil, número de filhos, etc.). No caso do presente trabalho, a escolha binária trata-se do indivíduo pertencer ou não à condição "Nem-Nem".

Esta metodologia está dividida em três tópicos, o primeiro explica o modelo de estimação utilizado no trabalho, o segundo explica os testes de consistência do modelo utilizado e o último contém a descrição dos dados e das variáveis. Todos os procedimentos aqui executados foram através da utilização do software estatístico Stata/SE 12.1.

\subsection{Modelo Probit}

O modelo probit é baseado na utilização de uma variável latente $I_{i}$ determinada por uma ou mais variáveis explanatórias $X_{i}$. É através dessa variável latente, ou índice de utilidade observável, que se pode determinar qual a decisão da i-ésima observação do modelo, ou seja, quanto maior o valor do índice $I_{i}$, maior a probabilidade de uma decisão positiva para a observação. Gujarati (2006) define este índice $I_{i}$, como:

$$
I_{i}=\beta_{1}+\beta_{2} X_{1}
$$

Seja $Y=1$ para indivíduos na condição "Nem-Nem" e $Y=0$ para caso contrário. Considerando que o índice $I_{i}$ possua um nível critico ou limiar $I_{i}^{*}$, que atua como um limite, tal que, se $I_{i}^{*}$ for menor ou igual a $I_{i}$, o indivíduo pertencerá à condição "Nem-Nem", e caso contrário não. Esse limiar $I_{i}^{*}$ não é uma variável observável como o índice $I_{i}$, mas supondo que o modelo se distribua de forma normal e com a mesma média e variância, além de ser possível estimar os parâmetros do índice dado em (1), também será possível obter algumas informações sobre o próprio índice não observável.

$$
Y= \begin{cases}1, \text { se } & I_{i}^{*} \leq I_{i} \\ 0, \text { se } & I_{i}^{*}>I_{i}\end{cases}
$$

Seguindo a premissa de normalidade, a probabilidade de que $I_{i}^{*}$ seja menor ou igual a $I_{i}$ pode ser calculada a partir da função de distribuição ou densidade de probabilidade acumulada (FDA) normal padronizada, expressa em (3).

$$
P_{i}=P(Y=1 \mid X)=P\left(I_{i}^{*} \leq I_{i}\right)=P\left(Z_{i} \leq \beta_{1}+\beta_{2} X_{i}\right)=F\left(\beta_{1}+\beta_{2} X_{i}\right)
$$

em que $P(Y=1 \mid X)$ é a probabilidade do individuo estar na condição "Nem-Nem" dado um ou mais valores da variável explanatória $X$ e onde $Z_{i}$ é a variável normal padronizada, isto é, $Z \sim N\left(0, \sigma^{2}\right)$. F é a FDA normal padrão, que é explicada em (4): 


$$
\begin{aligned}
F\left(I_{i}\right) & =\frac{1}{\sqrt{2 \pi}} \int_{-\infty}^{I_{i}} e^{-z^{2} / 2} d z \\
& =\frac{1}{\sqrt{2 \pi}} \int_{-\infty}^{\beta_{1}+\beta_{2} X_{i}} e^{-z^{2} / 2} d z
\end{aligned}
$$

Devido às características dos dados aqui utilizados foi necessária a utilização do modelo probit para dados individuais ou não agrupados. Para tanto, teve-se que recorrer ao procedimento de estimação não linear embasado no método de máxima verossimilhança.

Oliveira (1998), conclui que enquanto os parâmetros dos modelos de regressão linear comuns fornecem informações sobre o sentido, influência e grandeza da influência de uma variável explicativa, os parâmetros do modelo probit indicam de forma imediata somente o sentido da influência. Informações sobre a influência e grandeza da mesma necessitarão de cálculos adicionais.

Como visto no modelo probit, todos os regressores estão relacionados no cálculo da variação da probabilidade. Já a taxa desta variação, ou seja, a influência e grandeza da influência são dadas por $\beta_{j} f\left(Z_{i}\right)$, onde $f\left(Z_{i}\right)$ é a função de densidade da variável normal padrão e $Z_{i}=\beta_{1}+\beta_{2} X_{2 i}+\cdots+\beta_{k} X_{k i}$, isto é, o modelo de regressão utilizado na análise.

Para analisar a qualidade do ajustamento do modelo foi utilizado o Teste Hosmer-Lemeshow. Este teste vem com o objetivo de comprovar se o modelo proposto pode explicar de forma aceitável o fenômeno que se observa. O teste analisa o modelo ajustado comparando a distância entre as probabilidades ajustadas e as probabilidades observadas. Para tanto, irá dividir a amostra de acordo as probabilidades ajustadas com base nos valores dos parâmetros estimados, seguindo sempre a ordem do menor valor para o maior. Em seguida, separa estes grupos em tamanhos aproximadamente iguais. Se a amostra for separada em 10 grupos, o primeiro grupo será formado com as observações com probabilidade ajustada de até $10 \%$, o segundo com as observações com probabilidade ajustada de $10 \%$ a $20 \%$ e assim sucessivamente. Também foi utilizado o comando Estat Class, e é através desde comando que se encontra o percentual de acertos estimado do modelo.

\subsection{Descrição das variáveis}

Para o modelo utilizou variáveis consideráveis significantes para explicação da condição Nem-Nem. Os micro dados foram extraídos da PNAD 2012, a base de dados utilizada contou com 86.496 observações e 16 variáveis, conforme a Tabela $2^{3}$.

Tabela 2: Descrição das variáveis utilizadas no modelo

(continua)

\footnotetext{
${ }^{3}$ Variáveis com (*) são variáveis binárias, ou seja, são alimentadas com o valor 0 para respostas negativas e 1 para respostas afirmativas.
}

Revista de Estudos Sociais | Ano 2017, N. 38, V. 19, Pag. 117 


\begin{tabular}{|c|c|}
\hline Variável & Descrição da Variável \\
\hline SEXO* & Sexo do Indivíduo \\
\hline IDADE & Idade do Indivíduo \\
\hline ESCOLARIDADE & Anos de estudo \\
\hline SOLTEIRO* & Estado Civil \\
\hline Cor BRANCA* & \multirow{4}{*}{ Cor ou Raça } \\
\hline PRETA $^{*}$ & \\
\hline AMARELA* & \\
\hline PARDA* & \\
\hline RENDA & Faixa de rendimento mensal domiciliar per capita \\
\hline PROGSO & $\begin{array}{c}\text { Recebia normalmente juros de caderneta de poupança ou de } \\
\text { outras aplicações financeiras, dividendos, programas sociais } \\
\text { ou outros rendimentos. }\end{array}$ \\
\hline DOMESTICO* & Cuidava dos afazeres domésticos \\
\hline LER/ESCREVER & Sabe ler e escrever \\
\hline INTERNET & Nos últimos três meses, utilizou a Internet em algum local \\
\hline OUTREND & $\begin{array}{l}\text { Recebia normalmente rendimento que não era proveniente } \\
\text { de trabalho (pensão alimentícia ou de fundo de pensão, } \\
\text { abono de permanência, aluguel, doação, juros de caderneta } \\
\text { de poupança, dividendos ou outro qualquer). }\end{array}$ \\
\hline MORA com MAE & Mãe mora no domicílio \\
\hline Tem FILHO* & Se tem filho (a). \\
\hline
\end{tabular}

Fonte: Elaboração própria.

As variáveis para rodar o modelo foram escolhidas levando em consideração alguns autores presentes no referencial teórico desse trabalho, como Tillmann (2013), Monteiro (2013), Camarano e Kanso (2012).

Também se considerou a heterocedasticidade no modelo ao estimar pelo software Stata, utilizando o comando svy: hetprobit. O número de observações foi de 111.332, representando uma população de 61.019 .218 pessoas, em amostragem complexa.

\section{RESULTADOS}

A elaboração dos resultados desta pesquisa será dividida seguindo a ordem estabelecida dos objetivos específicos e gerais anteriormente definidos. Primeiro será feita uma comparação dos aspectos gerais da população "NemNem" para o caso do Brasil, América Latina e OCDE, em segundo momento serão utilizados os dados da PNAD 2012 para a elaboração do perfil dos jovens pertencentes à condição "Nem-Nem" e por último será extraído do modelo 
econométrico probit a influência que cada variável definida como perfil destes jovens tem sobre o fato de estarem ou não na condição "Nem-Nem".

4.1 Aspectos gerais da população Nem-Nem para o caso do Brasil, América Latina e OCDE.

Para iniciar a comparação da população na condição Nem-Nem, além de extraídos da PNAD, OCDE e OIT, utilizou dados de outros autores que já realizaram estudos sobre esse tema. Entre eles, Tillmann (2013), que distribuiu a população jovem brasileira em quatro categorias: os NEETs, os que estudam, os que trabalham, e os que estudam e trabalham. O gráfico 1 mostra a distribuição da população jovem brasileira.

Analisando a distribuição de Tillmann (2013) fica visível a disparidade entre a coluna representante dos homens e a das mulheres. A coluna com os dados dos homens tem por característica as extremidades achatadas e o centro longo, representando um alto nível de concentração de homens nas categorias que só trabalham ou só estudam, sendo os que só trabalham a maior parcela.

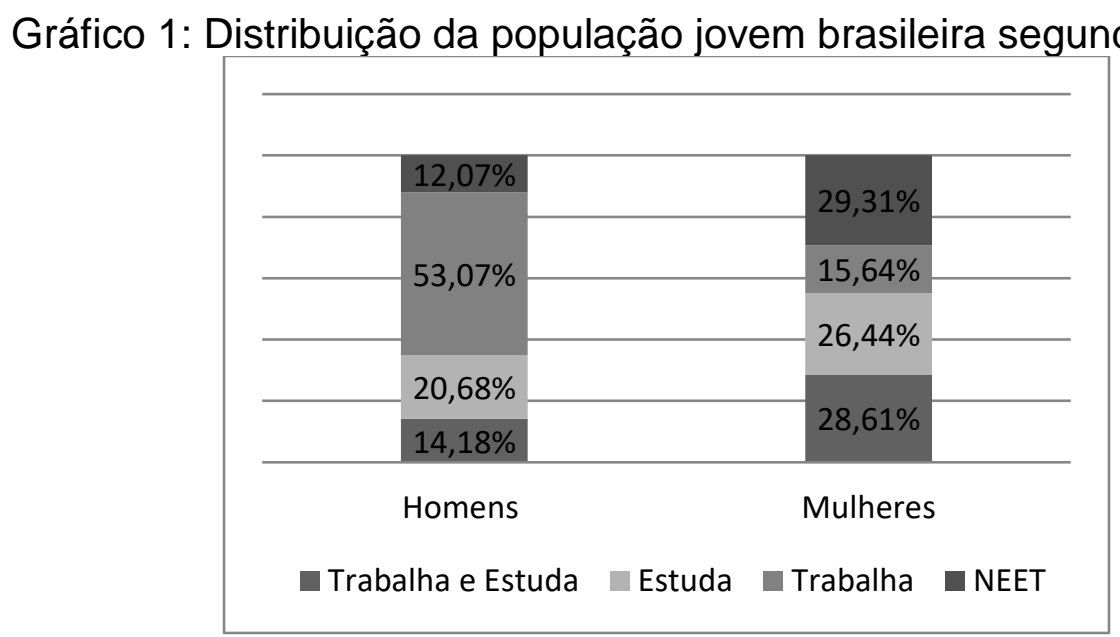

Fonte: Tillmann (2013).

A quantidade de homens existente nos grupos que estão estudando e trabalhando ao mesmo tempo ou homens pertencentes aos NEET é bem inferior em relação aos outros dois grupos. Já a coluna representante das mulheres mostra o contrário, com as extremidades longas e o centro mais achatado representa um alto nível de concentração de mulheres nos grupos que ou trabalham e estudam ao mesmo tempo ou não exercem nenhuma das duas atividades. O grupo representante das mulheres que só estudam é o terceiro em participação e o representante das que só trabalha é o menor deles, com apenas $15,64 \%$ das mulheres observadas.

A Organização Internacional do Trabalho também disponibiliza informações sobre as parcelas dos jovens ocupados e desocupados e dos vinculados ou não a alguma instituição de ensino. Para a comparação com os dados de Tillmann (2013), foi elaborado o Gráfico 2, agora mensurando a parcela população jovem da América Latina.

Revista de Estudos Sociais | Ano 2017, N. 38, V. 19, Pag. 119 
Gráfico 2: Distribuição dos jovens de 15 a 24 anos de idade: América Latina. (\%)

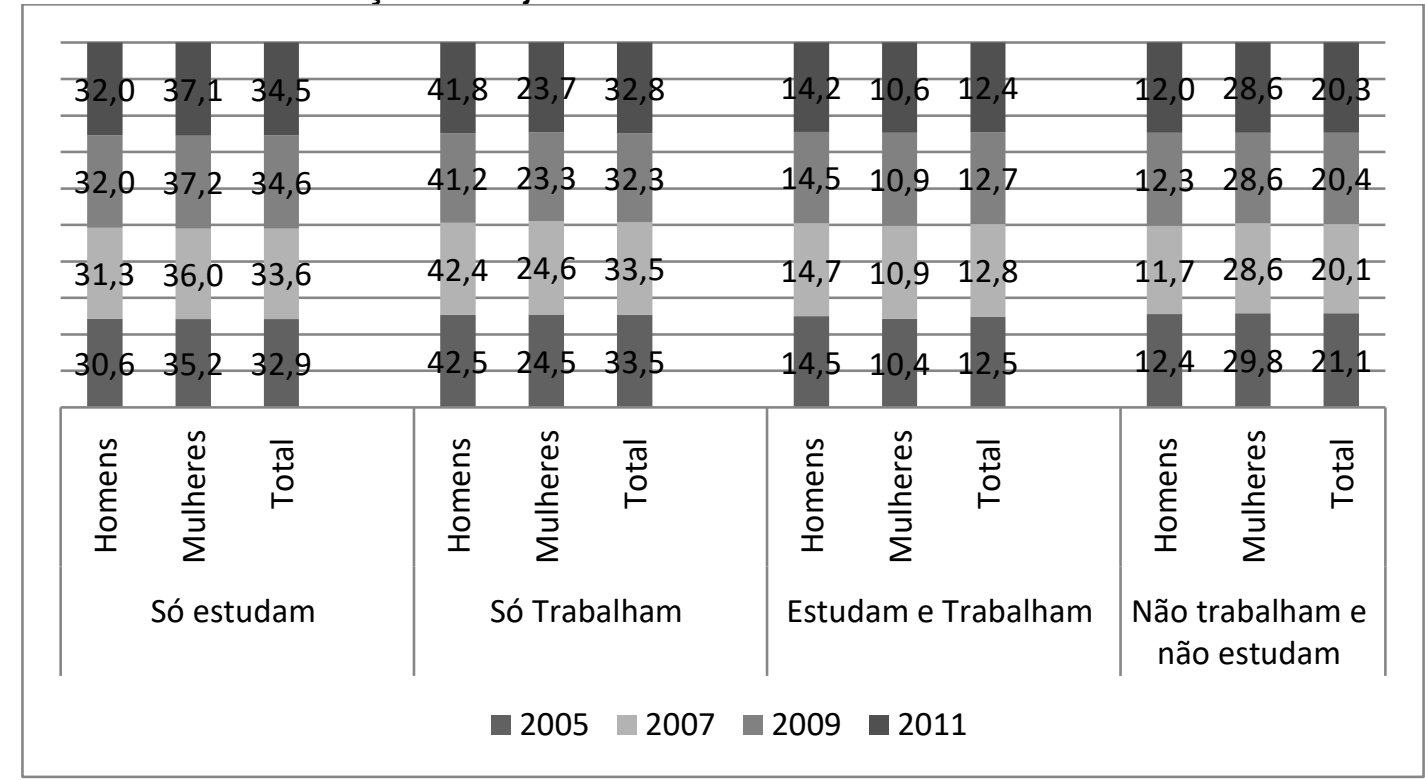

Fonte: Elaboração própria com dados da OIT.

Analisando o primeiro grupo, os que só estudam, é possível notar um aumento da proporção dos jovens pertencentes, tanto para os homens quanto as mulheres, na comparação dos anos de 2005 e 2011. Para o segundo grupo, os que só trabalham, o movimento migratório foi o contrário, dentro do período analisando houve uma perda de participação tanto de homens quanto mulheres. O terceiro grupo, os que estudam e trabalham, manteve-se próximo de uma constância, porém, o quarto e último grupo, o principal desta análise, sofreu uma pequena redução.

É possível notar, analisando cada linha do gráfico 2, como foi a evolução ano a ano e como esta população está se mostrando frente ao emprego e aos estudos. Do ano de 2005 para o ano de 2007 a proporção dos que só estudam e dos que estudam e trabalham aumentou ao mesmo tempo em que a proporção dos NEET diminuiu. Já do ano de 2007 a 2009, mesmo com a proporção dos que só estudam ainda aumentando, o grupo dos que estudam e trabalham diminuiu e os NEET sofreram um pequeno aumento. Na comparação dos dois últimos anos, de 2009 a 2011, os grupos dos jovens que só estudam, trabalham e estudam e os NEET, sofreram um pequeno recuo frente ao aumento do grupo dos que só trabalham.

Na distribuição elaborada por Tillmann (2013) e nos dados da OIT, nota-se que o percentual dos homens que não trabalham e não estudam no Brasil frente à média da América Latina, não tem uma variação que grande significância, cerca de $0,07 \%$, enquanto com as mulheres, a porcentagem é de $29,31 \%$ para $28,6 \%$ da América Latina.

Para a OCDE, o perfil das pessoas que não estão estudando e nem trabalhando varia muito de país para país. Em Israel e na Espanha, os homens jovens são mais propensos do que as mulheres jovens a serem NEET. Porém, ainda de acordo com a organização, o hiato de gênero é estreito, porque a atual recessão econômica afeta todos os jovens, independentemente do sexo. $\mathrm{Na}$ Turquia, o percentual das mulheres que estão mais propensas a ser "Nem-Nem" é

Revista de Estudos Sociais | Ano 2017, N. 38, V. 19, Pag. 120 
de $52 \%$, enquanto dos homens é $21 \%$, isso indica que as mulheres são duas vezes mais propensas que os homens a ser "Nem-Nem". A diferença de gênero é ainda maior no México: as mulheres jovens são três vezes mais propensas que os homens jovens, com os percentuais de $37 \%$ e $10 \%$, respectivamente. Estas grandes disparidades podem estar relacionadas à cultura, onde é provável que essas jovens optem por começar uma família ao em vez de seguir uma carreira. No Brasil, conforme a organização, a disparidade entre gêneros também é bem acentuada, dentre os homens, $11 \%$ estão propensos a ser um "Nem-Nem", já as mulheres são 27\%, ou seja, as mulheres são duas vezes mais propensas a entrar na condição não trabalha e não estuda. Os dados da OCDE, indicam novamente que mulheres são mais propensas a não trabalharem e não estudarem. Para Camarano e Kanso (2012), as mulheres serem mais propensas, leva a acreditar que exista um forte componente de gênero. Uma parte dessas mulheres possa ter constituído família e esteja desempenhando o tradicional de mãe e dona de casa. Na mesma linha, a OCDE afirma que as disparidades refletem escolhas de gênero mais tradicionais, em que as mulheres estão mais propensas a começar uma família ao invés de perseguir uma educação ou uma carreira.

No gráfico 3 tem-se o percentual dos jovens entre 15 a 29 anos classificados na condição "Nem-Nem" para os países pertencentes à OCDE. Os dados foram retirados de OECD (2012). 
Gráfico 3: Jovens na condição "Nem-Nem" para países da OCDE - 2010 (\%)

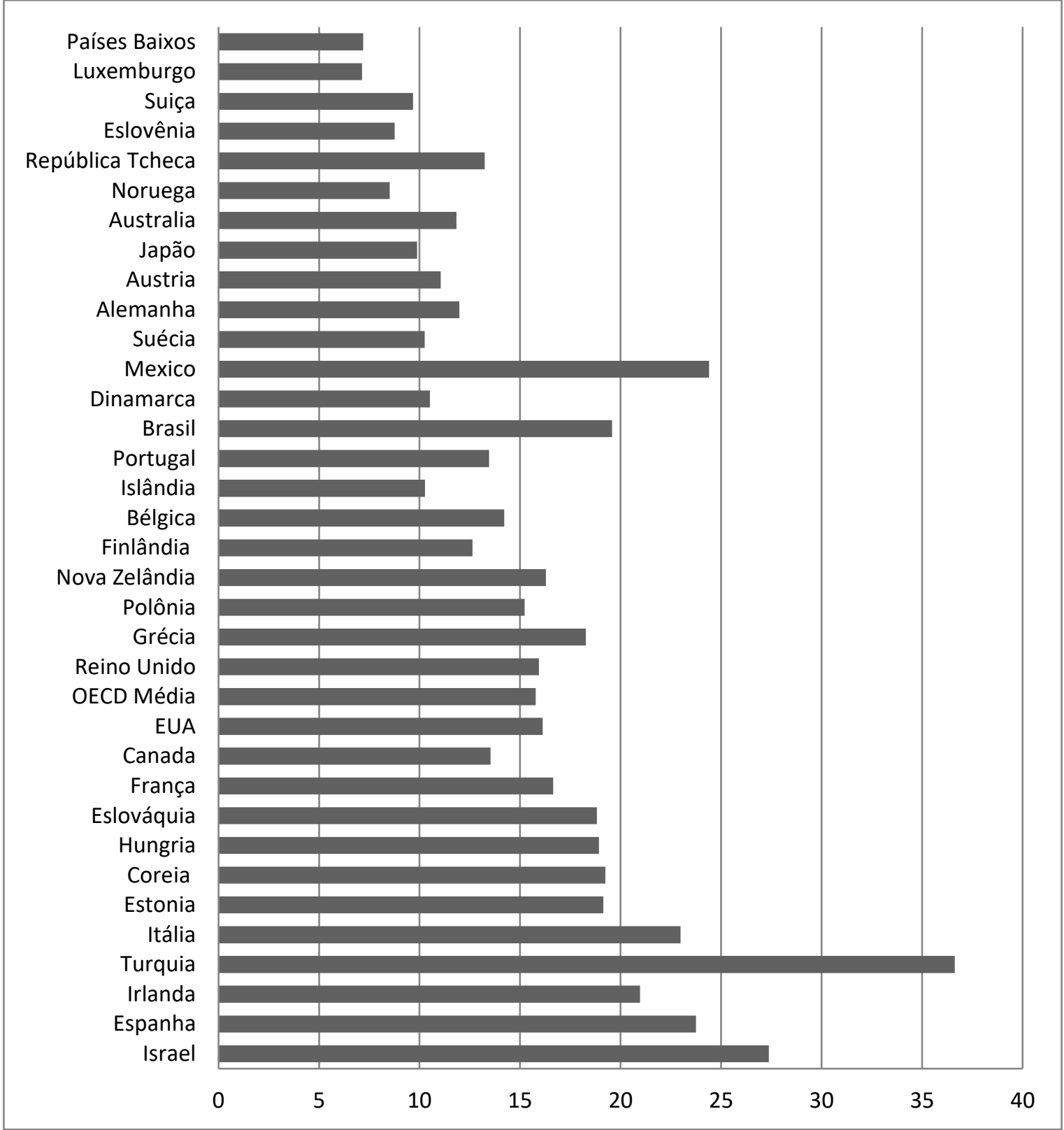

Fonte: Elaboração própria com dados da OECD (2012).

\subsection{O perfil dos jovens brasileiros na condição "Nem-Nem"}

Para a elaboração do perfil dos jovens brasileiros que estão na condição "Nem-Nem" o primeiro passo será a apresentação de características básicas como o contingente existente no Brasil, a população ocupada na semana de referência, os indivíduos que frequentam algum tipo de estabelecimento escolar e, por fim, os indivíduos que estão desocupados e não frequentam estabelecimentos de ensino.

De acordo com o IBGE a população jovem no Brasil, que incluem indivíduos com idades ente 15 a 29 anos, é constituída por aproximadamente 48,026 milhões representando $25 \%$ da população total brasileira. Um grupo com

Revista de Estudos Sociais | Ano 2017, N. 38, V. 19, Pag. 122 
número significativo e de grande importância na sociedade. De 2001 a 2011 observou-se um aumento no contingente jovem do país, já a partir de 2012 há um declínio desta população.

Verificando a população jovem, é possível notar algumas características básicas da população brasileira. A faixa etária predominante desta população, para o período analisado em questão, é a faixa dos 20 aos 24 anos. A comparação da quantidade de homens e mulheres mantêm, em média, as mesmas proporções da população total brasileira, sendo a quantidade de mulheres sempre superior a quantidade de homens.

Fazendo um comparativo entre a quantidade ocupada de homens e mulheres é possível notar a parcela dos homens ocupados sendo sempre superior à parcela das mulheres ocupadas, mesmo com a quantidade absoluta de mulheres pertencentes a estes grupos superior a quantidade dos homens.

Já analisando o quesito educação dentre os jovens de 15 a 17 anos, cerca de $84,3 \%$ frequentam algum tipo de estabelecimento escolar. Esse percentual cai para 30,1\% entre os indivíduos de 18 a 24 anos de idade. Os indivíduos de 25 a 29 anos de idade não foram observados, pois os dados publicados pelo IBGE agrupam os indivíduos com idade superior a 25 anos.

Com os dados da PNAD 2011, foi possível observar que $21,08 \%$ da população jovem brasileira estão na condição Nem-Nem, um percentual que significa que a cada cinco jovens um não está estudando e nem trabalhando. Dentre os que estão nessa condição, $70,52 \%$ pertencem ao sexo feminino. Cerca de $42 \%$, entre os Nem-Nem, possuem algum filho vivo.

Considerando a faixa etária dos jovens, observou-se que a maioria dos jovens que não estuda e não trabalham concentram a partir dos 18 anos a 29 anos. De acordo com a divisão do sistema de educação brasileiro, aos 17 anos o indivíduo conclui o ensino médio, iniciando assim a transição para a vida adulta, ou seja, saída da escola e entrada no mercado de trabalho, conforme abordado por Vieira (2009) anteriormente. Esse período de transição pode gerar o desemprego juvenil, explicado por Cardoso (2013). O desemprego juvenil pode explicar o jovem que não trabalha e não estuda na faixa etária dos 17 aos 18 anos. Quanto aos jovens de 18 a 29 anos, a proporção de Nem-Nem por idade manteve-se quase que consta com $7,48 \%$.

Quanto à escolaridade dos jovens na condição Nem-Nem, a maioria, $38,47 \%$ possuem pelo menos 12 anos de estudo, equivalente ao ensino fundamental e o médio. Seguido por aqueles que possuem somente o ensino fundamental, 9 anos de estudo, um montante de 12,77\%. E por fim, também com representação significativa aqueles que não possuem nenhum grau de instrução ou tem pelo menos um ano de estudo com $8,82 \%$. Embora, a quantidade os que não possuem instrução seja representativa, 95,29\% dos Nem-Nem sabem ler e escrever.

A faixa de renda domiciliar per capita da maioria, está entre $1 / 4$ até $1 / 2$ salário mínimo com 29,26\%, seguido por aquelas famílias que recebem de $1 / 2$ até 1 salário mínimo, 28,74\%. A porcentagem dos jovens na condição Nem-Nem, que cuidava de afazeres domésticos na semana de referência foi de $76,12 \%$. No entanto, quando observado o estado civil, cerca de $80,53 \%$ são solteiros (as), a minoria $3,91 \%$ são casados.

Revista de Estudos Sociais | Ano 2017, N. 38, V. 19, Pag. 123 
Dentre os jovens que não trabalham e não estudam, a raça que mais predomina no subgrupo populacional é a parda com $53,25 \%$, seguido pelos brancos, $36,34 \%$, e pelos pretos com $9,34 \%$. Tanto os amarelos quanto os indígenas não apresentam quantidades de jovens significativas.

A partir das estatísticas descritivas, traçou-se o perfil do jovem que não trabalha e não estuda, desta forma, nota-se que atualmente esse jovem apresenta as seguintes características: É mulher, cuida dos afazeres domésticos, possui filhos e possui baixo nível de renda. Monteiro (2013) em seu estudo chegou a características bem semelhantes as aqui apresentas. Para Monteiro (2013) a condição nem-nem é mais preponderante entre jovens com baixa escolaridade e de baixa renda, e mulheres, especialmente as com filho. Quase metade dos jovens na condição nem-nem são mulheres com filhos que estão em casa.

Segue a tabela 3 com o perfil dos jovens Nem-Nem.

Tabela 3: Perfil da População Nem-Nem PNAD (2011).

\begin{tabular}{c|c|r}
\hline Variável & Descrição & $\%$ \\
\hline Nem-Nem & Indivíduos que estão ou não na condição Nem-Nem & 21,08 \\
\hline \multirow{2}{*}{ Sexo } & Homem & 29,47 \\
\cline { 2 - 3 } & Mulheres & 70,53 \\
\hline \multirow{4}{*}{ Filho } & Possuem filhos & 42,04 \\
\cline { 2 - 3 } & 15 anos & 2,08 \\
\cline { 2 - 3 } & 16 anos & 3,24 \\
\cline { 2 - 3 } Escolaridade & 17 anos & 4,97 \\
\cline { 2 - 3 } & 18 a 29 anos & 7,48 \\
\cline { 2 - 3 } & 1 ano de estudo & 8,82 \\
\hline \multirow{3}{*}{ Ler e Escrever } & 9 anos de estudo & 12,77 \\
\hline \multirow{2}{*}{ Renda } & 12 anos de estudo & 38,47 \\
\cline { 2 - 3 } & Sabe ler e escrever & 95,29 \\
\hline \multirow{2}{*}{ Domestico } & Mais de $1 / 4$ até $1 / 2$ salário mínimo & 29,26 \\
\hline \multirow{2}{*}{ Estado Civil } & Mais de $1 / 2$ até 1 salário mínimo & 28,74 \\
\cline { 2 - 3 } & Cuidava dos afazeres domésticos & 76,12 \\
\hline \multirow{3}{*}{ Cor ou Raça } & Solteiro & 80,53 \\
\cline { 2 - 3 } & Casado & 3,91 \\
\cline { 2 - 3 } & Branco & 36,34 \\
\cline { 2 - 3 } & Preto & 0,34 \\
\cline { 2 - 3 } & Amarela & 0,52 \\
\cline { 2 - 3 }
\end{tabular}

Fonte: Elaboração própria com dados da PNAD. 


\subsection{Análise da influência de cada característica: modelo probit}

O modelo probit foi aplicado e a partir dos primeiros resultados obtiveramse informações referentes ao sentido da influência que cada variável teria na probabilidade do indivíduo i-ésimo estar ou não na condição "Nem-Nem".

Juntamente com o sentido da influência, as informações referentes à amostra, justificando assim a continuação da extração de informações do modelo, ou seja, mostrando qual o grau de explicação do modelo e que o mesmo estava bem ajustado. É importante relembrar que os valores dos parâmetros estimados para o modelo probit significam a contribuição individual das variáveis no índice de utilidade que não é observável, mas que está relacionado com a probabilidade de o evento ocorrer.

Objetivando um melhor ajustamento do modelo, estimou-se um modelo probit com correção de heterocedasticidade. O modelo probit padrão foi ajustado pela presença de heterocedasticidade utilizando as variáveis "domestico" e "tem filho". Assim, chega-se a um modelo com valor da probabilidade (Prob $>|t|$ de cada variável) inferiores a $0.05 \mathrm{em}$ todos os coeficientes estimados.

Todos os valores apresentados foram retirados da PNAD 2012 reponderada em 14/08/2015 e nela executada a expansão dos dados através do comando "survey". A tabela 4 traz os resultados da aplicação do modelo probit.

Tabela 4: Resultados obtidos para o modelo probit.

\begin{tabular}{|c|c|c|c|c|}
\hline Variável & Coeficiente & Erro-padrão & Estat. $t$ & Prob $>|t|$ \\
\hline Sexo & $-0,45084$ & 0,02470 & $-18,250$ & 0,000 \\
\hline Idade & 0,02173 & 0,00152 & 14,260 & 0,000 \\
\hline Escolaridade & $-0,03164$ & 0,00249 & $-12,710$ & 0,000 \\
\hline Renda & $-0,00124$ & 0,00030 & $-4,170$ & 0,000 \\
\hline Domestico & 0,47628 & 0,03369 & 14,140 & 0,000 \\
\hline Ler/escrever & $-0,35590$ & 0,04226 & $-8,420$ & 0,000 \\
\hline Internet & $-0,28469$ & 0,01849 & $-15,400$ & 0,000 \\
\hline Mora com mãe & 0,03052 & 0,00580 & 5,260 & 0,000 \\
\hline Tem filho & 0,06446 & 0,02394 & 2,690 & 0,007 \\
\hline Cor Branca & 0,06250 & 0,00921 & $-6,790$ & 0,000 \\
\hline Desquitado & $-0,18524$ & 0,07261 & $-2,550$ & 0,011 \\
\hline Divorciado & $-0,14872$ & 0,05054 & $-2,940$ & 0,003 \\
\hline Solteiro & $-0,04400$ & 0,01276 & $-3,450$ & 0,001 \\
\hline Intercepto & $-0,50698$ & 0,05749 & $-8,820$ & 0,000 \\
\hline \multicolumn{5}{|l|}{ Insigma2 } \\
\hline Domestico & $-0,44473$ & 0,04236 & $-10,500$ & 0,000 \\
\hline Tem filho & 0,06067 & 0,04227 & 1,440 & 0,151 \\
\hline \multirow{2}{*}{\multicolumn{2}{|c|}{$\begin{array}{l}F(14,5598)=159,76 \\
\text { Número de observações }=86496 \\
\text { Tamanho da População }=46966837\end{array}$}} & \multirow{2}{*}{\multicolumn{2}{|c|}{$\begin{array}{l}\text { Prob }>F=0,0000 \\
\text { Projeto } d f=5570\end{array}$}} & \\
\hline & & & & \\
\hline
\end{tabular}

Fonte: Resultados da pesquisa. Dados básicos da PNAD 2012/IBGE. 
Este resultado mostra o sentido da influência que cada variável terá sobre a variável dummy dependente. Nas variáveis com influência negativa, ou seja, aquelas que influenciarão o indivíduo a não estar na condição estudada, estão a maioria das variáveis do modelo, sendo elas: "sexo", "escolaridade", "renda", "ler/escrever", "internet", "desquitado", "divorciado", "solteiro". As variáveis "idade", "domestico", "mora com a mãe", "tem filho" e "cor branca" são as com influência positiva, aquelas que contribuirão para indivíduo estar na condição estudada.

Para saber além do sentido da influência, foi extraído o efeito marginal que cada variável terá sobre a variável dependente. Podendo assim concluir o percentual de influência de cada variável do modelo, apontando as que mais influenciam positivamente ou negativamente e também as que menos influenciam (Tabela 5).

Tabela 5: Efeito Marginal das variáveis, com correção para heterocedasticidade.

\begin{tabular}{|c|c|c|c|c|c|}
\hline Variável & $d y / d x$ & Erro-Padrão & $\mathbf{z}$ & Prob. $>|z|$ & $X$ \\
\hline Sexo* & $-0,14177$ & 0,00345 & $-41,110$ & 0,000 & 0,50113 \\
\hline Idade & 0,00684 & 0,00041 & 16,700 & 0,000 & 21,77750 \\
\hline Escolaridade & $-0,00995$ & 0,00060 & $-16,620$ & 0,000 & 10,37020 \\
\hline Renda & $-0,00039$ & 0,00009 & $-4,260$ & 0,000 & 7,41158 \\
\hline Domestico* & 0,03463 & 0,00354 & 9,790 & 0,000 & 0,63496 \\
\hline Ler/Escrever* & $-0,13424$ & 0,01616 & $-8,300$ & 0,000 & 0,98274 \\
\hline Internet ${ }^{\star}$ & $-0,09572$ & 0,00426 & $-22,490$ & 0,000 & 0,70333 \\
\hline Mora Com a Mãe & 0,00960 & 0,00174 & 5,520 & 0,000 & 2,80518 \\
\hline Tem Filho* & 0,03428 & 0,00538 & 6,370 & 0,000 & 0,89020 \\
\hline Branca* & $-0,01958$ & 0,00275 & $-7,120$ & 0,000 & 0,44191 \\
\hline Desquitado* & $-0,05179$ & 0,01777 & $-2,910$ & 0,004 & 0,00341 \\
\hline Divorciado* & $-0,04263$ & 0,01312 & $-3,250$ & 0,001 & 0,00740 \\
\hline Solteiro* & $-0,01410$ & 0,00423 & $-3,340$ & 0,001 & 0,84885 \\
\hline
\end{tabular}

Fonte: Resultados da pesquisa. OBS: * dy/dx é para a mudança discreta da dummy 0-1; $y=\operatorname{Pr}($ nemnem) (predict) $=0,16718717$.

Dentre homens e mulheres, o fato de ser homem diminui em $14,2 \%$ na probabilidade do indivíduo de não estar na condição estudada. Cada ano a mais de escolaridade que o indivíduo tenha diminui em $1 \%$ esta probabilidade. Indivíduos que sabem ler e escrever, reduzem suas probabilidades em 13,4\%. As outras variáveis que possuem efeitos negativos são: Ter acesso à internet ($9,6 \%)$, ser da etnia branca (-2\%), estar desquitado $(-5,2 \%)$, estar divorciado ($4,3 \%)$ ou estar solteiro $(-1,4 \%)$. A variável "renda" também apresenta sentido negativo, porém, com um efeito marginal muito baixo $(-0,04 \%)$ a cada aumento de nível de renda.

Dentre as variáveis que apresentam efeito positivo sobre a probabilidade, nota-se que o fato ter um ou mais filhos contribui e 3,4\%, ter realizado trabalho doméstico em 3,5\%, a mãe morar na residência em $1 \%$ e cada ano de vida a mais do indivíduo representa um aumento de 0,7\%. As variáveis "amarelo", "preto" e "pardo" foram retiradas do modelo por apresentarem ajustamentos indesejados.

Revista de Estudos Sociais | Ano 2017, N. 38, V. 19, Pag. 126 
Com os resultados encontrados, pode-se afirmar que as características que mais influenciam o indivíduo ser um Nem-Nem, são "sexo", "escolaridade", "ler/escrever", "internet" e "desquitado".

Para Camarano e Kanso (2012), no caso das mulheres, o estado conjugal e maternidade são fatores que parecem associados à condição de não trabalhar e não estudar, o que determinaria uma transição para a vida adulta diferenciada para cada sexo.

Para o MDS, a jovem tende a deixar a escola e o mercado de trabalho na fase inicial da maternidade, quando os filhos são menores. Um dos motivos para que as mulheres fiquem em função da maternidade está associado à cobertura de creche no Brasil, para a faixa etária de 0 a 3 anos, a cobertura de creche no Brasil é pequena, cerca de $21 \%$.

\section{CONCLUSÃO}

A análise do perfil do jovem brasileiro entre 15 a 29 anos de idade que se encontra na condição Nem-Nem, mostrou poucas ou nenhuma divergência com base nos principais autores sobre o assunto. A ideia inicial desse estudo era acima de tudo conhecer quem era o contingente da população que não estava no mercado de trabalho e muito menos em uma rede de ensino, a fim de propor possíveis políticas públicas, para que com o intermédio do estado, pudéssemos retornar esses jovens ao mercado de trabalho ou aos bancos da escola. Ao decorrer do estudo, dificuldades foram encontradas e novos objetivos foram sendo traçados.

Por ser um tema novo e ainda pouco discutido, o fenômeno da população que não trabalha e não estuda se não for tratado com atenção necessária pode trazer grandes prejuízos tanto no âmbito econômico quanto no social. O estudo revelou que a grande maioria dos jovens que estão na condição Nem-Nem, são mulheres. Em médio prazo as mulheres que optam por deixar seus empregos e seguir com a "carreira de mãe" conseguirão seus postos de trabalho no futuro? Além disso, deve-se salientar que a maioria desses jovens possui uma renda baixa e pouco estudo. A fim de propor novos estudos sobre o tema, cabe uma futura análise sobre o mercado de trabalho para as mulheres que tenham se dedicado à família, embora que temporariamente.

A população Nem-Nem no Brasil, diferentemente dos outros países, conforme verificado, não originou de uma crise econômica e ou em consequência da falta de emprego. A origem dos Nem-Nem no Brasil, está fortemente vinculada com as escolhas e trajetórias de vida adulta. Assim, em concordância com MDS, o fenômeno no Brasil tem características específicas que sugerem um desenho de política que combine preferencialmente proteção social e educação.

\section{REFERÊNCIAS BIBLIOGRÁFICAS}

CAMARANO, A. A.; CARVALHO, D. F. O que estão fazendo os homens maduros que não trabalham, não procuram trabalho e não são aposentados? Ciência \& Saúde Coletiva, v. 20,n. 9, 2015. pp. 2757-2764.

Revista de Estudos Sociais | Ano 2017, N. 38, V. 19, Pag. 127 
CAMARANO, A. A.; FERNANDES, D. O que estão fazendo os homens maduros que não trabalham, não procuram trabalho e não são aposentados? Boletim Mercado de Trabalho, n.57, Rio de Janeiro: IPEA, Ago., 2014. pp. 21-30.

CAMARANO, A. A.; KANSO, S. O que estão fazendo os jovens que não estudam e nem trabalham? Boletim Mercado de Trabalho - Conjuntura e Análise n. 53, Rio de Janeiro: IPEA, Nov., 2012.

CAMARANO, A. A.; MELLO, J.L.; PASINATO, M.T.; KANSO, S. Caminhos para a vida adulta e as múltiplas trajetórias dos jovens brasileiros. Texto para discussão n. 1038. Rio de Janeiro: IPEA, 2004.

CAMARANO, Ana Amélia (Organizadora). Transição para a vida adulta ou vida adulta em transição? - Rio de Janeiro: IPEA, 2006. 332 p.: il.

CARDOSO, A. Juventude, Trabalho e Desenvolvimento: elementos para uma agenda de investigação. CADERNO CRH, Salvador: UFBA, v. 26, n. 68, pp. 293314, Maio/Ago. 2013.

CASTRO, J.A.; AQUINO, L.M.C.; ANDRADE, C.C. (orgs.) Juventude e políticas sociais no Brasil. Brasília: IPEA, 2009. 303 p.

COLES, B.; HUTTON, S.; BRADSHAW, J.; CRAIG, G.; GODFREY, C.; JOHNSON, J. Literature Review of the Costs of being Not in Education, Employment or Training at Age 16-18. Research Report, n. 347, Norwich : Queen's Printer, Jun. 2002

CORSEUIL, C. H.; SANTOS, C.D. ; FOGUEL, M.N. Decisões críticas em idades críticas: A escolha dos jovens entre estudo e trabalho no brasil e em outros países da América Latina. Texto para discussão no 797. Rio de Janeiro: IPEA, 2001. 51 p.

DORSETT, R.; LUCCHINO, P. Snakes and ladders in the youth labour market. IFS-PEPA workshop "Applied policy evaluation, with a focus on dynamic issues and duration modelling", London: National Institute of Economic and Social Research, Jun. 2012. 40p.

IBGE - INSTITUTO BRASILEIRO DE GEOGRAFIA E ESTATÍSTICA. Pesquisa Nacional de Amostragem de Domicílios, Rio de Janeiro: IBGE, 2012.

JACCOUD, L.; HADJAB, P.D.E.; ROCHET, J. A Política de Assistência Social e a Juventude: um diálogo sobre a vulnerabilidade social? In: CASTRO, J.A.;

AQUINO, L.M.C.; ANDRADE, C.C. (org.). Juventude e Políticas Sociais no Brasil, Brasília: Ipea, 2009.

MDS - MINISTÉRIO DO DESENVOLVIMENTO SOCIAL E COMBATE À FOME. Os Jovens que não estudam nem trabalham no Brasil: discussão conceitual, caracterização e evolução de 2001 a 2011. Estudo Técnico 03/2013. Brasília. 2013a. 22p.

MDS - MINISTÉRIO DO DESENVOLVIMENTO SOCIAL E COMBATE À FOME. Os Jovens que não estudam nem trabalham no Brasil e o Bolsa Família. Estudo Técnico 15/2013. Brasília. 2013b. 22p.

Revista de Estudos Sociais | Ano 2017, N. 38, V. 19, Pag. 128 
MONTEIRO, J. Quem são os jovens Nem-Nem?: uma análise sobre os jovens que não estudam e não participam do mercado de trabalho. Texto para Discussão n.34, Rio de Janeiro: FGV-IBRE, Set. 2013.

MORESI, Eduardo (org.). Metodologia da Pesquisa. Brasília: Universidade Católica de Brasília, 2003. 108p.

OLIVEIRA, M. M. Modelos de escolha binária. Faculdade de Economia do Porto, Portugal. 1998.

OECD, Education at a Glance 2012: OECD Indicators, OECD Publishing. 2012.

OIT. Trabajo Decente y Juventud en América Latina. 2013. Lima: OIT / Oficina Regional para América Latina y el Caribe, 2013, 288 p.

PARDO, M. S. Jóvenes que ni estudian ni trabajan: un riesgo para la cohesión social em America Latina. DIAZ, F.J.; MELLER, P. (eds.). Violencia y Cohesión Social en América Latina. Santiago, Chile: CIEPLAN, 2012. pp.161-208.

QUARINA, Q. An analysis of the determinants and scarring effects of economic inactivity and unemployment in the UK. Lancaster: Lancaster University. Thesis (Economics). Feb. 2017. 340p.

RALSTON, K.; FENG, Z.; EVERINGTON, D.; DIBBEN, C. Do young people not in education, employment or training experience long-term occupational scarring? A longitudinal analysis over 20 years of follow-up. Contemporary Social Science, v.11, n.2-3, 2016. pp. 203-221.

SADLER, Who are the young people who are not in education, employment or training? An application of the risk factors to a rural area in the UK. International Social Work, v. 58, n. 4, 2015, pp. 508-520.

SAMOILENKO, A.; CARTER, K. Economic Outcomes of Youth not in Education, Employment or Training (NEET), New Zealand Treasury Working Paper 15/01, Mar. 2015. 34p.

SILVA, P. L. N.; PESSOA, D.G.C. ; LILA, M.F. Análise estatística de dados da PNAD: incorporando a estrutura do plano amostral. Ciência \& Saúde Coletiva, vol. 7, n.4, 2002. pp. 659-670.

TILLMANN, Eduardo André. Escolaridade, rendimentos e desigualdade de gênero entre os jovens no Brasil. Dissertação (Mestrado). Porto Alegre: Universidade Federal do Rio Grande do Sul, 2013. 69p.

TILLMANN, E.A.; COMIM, F. Os determinantes da decisão entre estudo e trabalho dos jovens no Brasil e a geração Nem-Nem. Pesquisa e Planejamento Econômico, v. 46, n. 2, Ago. 2016, pp. 47-78.

VIEIRA, Joice Melo. Transição para a vida adulta em São Paulo: Cenários e tendências sócio demográficas. Tese (Doutorado). Campinas: Universidade Estadual de Campinas, 2009. 222 p. 